\title{
Laboratory evaluation of entomopathogenic fungus alone or in combination with edible oils on progeny adult build- up of lesser grain borer on stored paddy
}

\author{
P. JYOTHI ${ }^{1}$, N. SAMBASIVA RAO ${ }^{2}$ AND R. LAKSHMIPATHY ${ }^{3}$ \\ ${ }^{1}$ Department of Entomology, Agricultural College Campus, BAPATLA (A.P.) INDIA \\ ${ }^{2}$ Post Harvest Technology Centre, Agricultural College Campus, BAPATLA (A.P.) INDIA \\ ${ }^{3}$ Microbiology Laboratory, Agricultural College Campus, BAPATLA (A.P.) INDIA
}

The entomopathogenic fungi, Beauveria bassiana $\left(2 \times 10^{6}\right.$ conidia/g), Metarhizium anisopliae $\left(1 \times 10^{9}\right.$ conidia/g) and Lecanicillium lecanii ( $2 \times 10^{7}$ conidia/g) @ $5 \mathrm{~g} / \mathrm{l}$ as bag treatment and $5 \mathrm{~g} / \mathrm{kg}$ of paddy as grain treatment alone, their interactions and the compatibility of entomopathogenic fungi @ $5 \mathrm{~g} / \mathrm{kg}$ with two vegetable oils $(2 \mathrm{ml} / \mathrm{kg})$ viz., sunflower oil and groundnut oil were tested against the progeny build-up of lesser grain borer, $R$. dominica. In the grain treatment, least progeny of 122.33 was observed with $B$. bassiana followed by $M$. anisopliae (130.67) which were at par at 180 DAT. Among the bag treatment, M. anisopliae recorded the lower progeny of 266.33 followed by B. bassiana (291.00) and L. lecanii (298.67) which were at par with each other but were significantly different from control (366.33). In the study of interaction effects, Beauveria + Metarhizium + Lecanicillium had recorded least progeny of 119.67 followed by Beauveria + Metarhizium (122.00) and were superior over all other treatments. In the study of compatibility of entomopathogenic fungi with edible oils, progeny build up recorded at 180 DAT was found to be less with Beauveria + Groundnut oil (118.33) followed by Metarhizium + Groundnut oil (121.33) compared to oils alone, sunflower (307.67) and groundnut (252.33) but were significantly different from control (517.00).

Key words : Beauveria, Lecanicillium, Metarhizium, Rhyzopertha dominica, Sunflower oil

How to cite this paper : Jyothi, P., Rao, N. Sambasiva and Lakshipathy, R. (2014). Laboratory evaluation of entomopathogenic fungus alone or in combination with edible oils on progeny adult build-up of lesser grain borer on stored paddy. Asian J. Bio. Sci., 9 (2) : 139-145. 